\section{ON THE RESPIRATORY NEUROSES. ${ }^{1}$}

BY SAMUEL WEST, M.D. OXON., F.R.C.P. LoND., PATSICIAN TO ST. BARTHOLOMEW'S HOSPITAL, ETC.

The respiratory morements in heniplegia. - In 1894 Hughlings Jackson directed attention to the alterations in the respiratory movements observed in hemiplegia. He stated that there was a marked difference in the cases between ordinary quiet breathing and deep or. forced breathing. Thus, on ordinary breathing, if any difference between the two sides was to be observed, it was that the movements on the affected side were somewhat increased, whilst on deep or forcible breathing the movements of the affected side were markedly diminished. From these facts he drew the following conclusions. That the respiratory movements are of two orders-the one automatic, chiefly diphragmatic; the other voluntary, chiefly costal; and that they have their controlling centres in different parts of the nervous system-the antomatic in the medulla (the so-called respiratory centre) and the voluntary in the brain, the fibres from which run in the same tract as those to the limbs. Thus, when a healthy person is lying in bed and breathing quietly, the movements are abdominal or diaphragmatic. If told to take a deep breath the type of respiration is entirely altered; the movements cease to be abdominal and become almost entirely costal; in other words, the automatic centre is inhibited and the control taken over for the time by the higher voluntary centres.

About three years ago $I$ had a very interesting case of hemiplegia, which exhibited many of the changes described in $\mathbf{a}^{*}$ remarkable degree. I show the tracings obtained. (Fig.1.) On ordinary quiet breathing little difference was

FIG. 1.

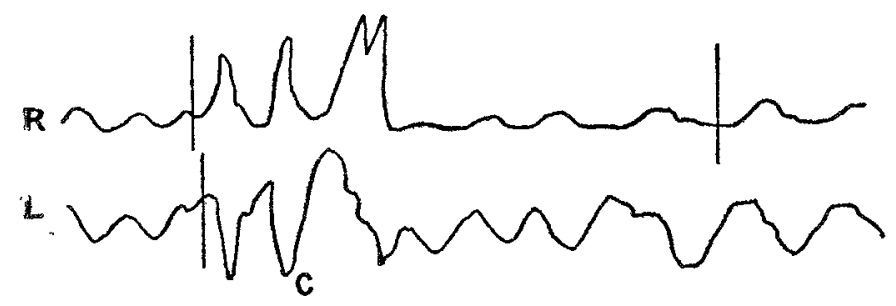

Tracing showing the movements of the two sides of the chest in a case of right hemiplegiz. The strainht lines show the parts of the tracings which correspond. The tracings show that on ordinary breathing the hemiplegic side moves less than the sound side; on forced breathing (coughing, c) the curves are inverted. R, Right side. L, Left side.

to be seen between the movements of the two sides, but what difference there was was against the affected side. On the patient being told to take a deep breath the differences became very considerable. They were most remarkable when the patient coughed. Then the deep inspiration which was the prelude to the cough was well marked on the soun side, and almost absent on the affected side. At the time of cough the expiratory contraction was well marked on the sound side, but absent on the affected side; and the intercostal spaces on this side, offering no muscular resistance, were violently forced out. This gave a very peculiar feeling to the hand placed upon the side, and showed itself upon the tracing in a very remarkable inverted curve.

I take the opportunity of showing, although it does not bear directly upon the subject of discussion, the alteration in shape of the affected side of the thorax. (Fig. 2.) This was markedly flattened, from which we may conclude that the normal shape of the chest is the position of equilibrium between the two sets of opposing muscles. When these museles are paralysed the side fiattens. It is possible thit the actual shape may vary with the position in which the patient may happen to be lying. It is obvious, of course that the respiratory movements are, and must be, very largely under direct and immediate cerebral control. What Hughlings Jackson maintained was that this control mu-t be represented in some cerebral cortical centre, as are the other voluntary movements of the body. I believe that it minst be in these higher respiratory centres th $t$ t the explanation of the respiratory neuroses must be looked for.

1 The introduction to a discussion on the subject at tue Meitical Society of London on Nov. 11th, 1912.
The neuroses of the respiratory organs fall into two groups, according as they are, or are not, associated with, or lead to, dyspncea and its consequences-viz., cyanosis and suffocation. In the first group those with dyspnoea and cyanosis are found: (1) asthma; (2) laryngismus stridulus

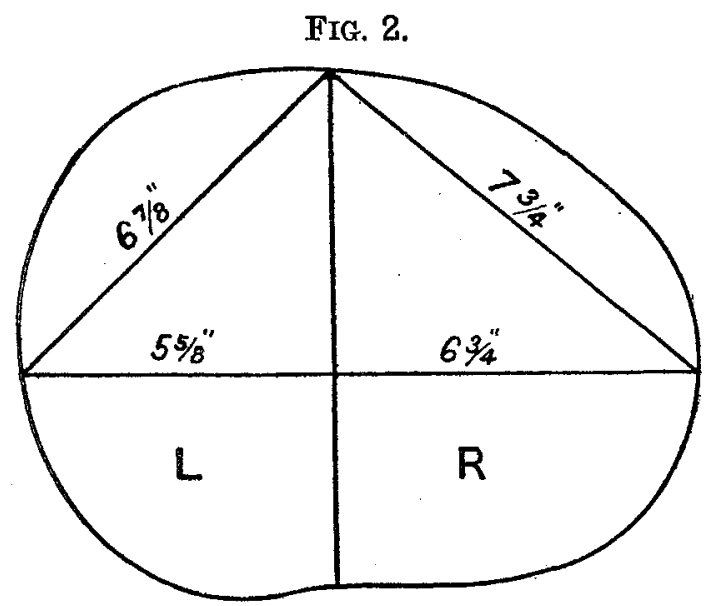

Tracing showing the flattening of the right (hemiplegic) side.

Measurements are given in inches. $R$, Right side. $L$, Left side.

and some other laryngeal spasms ; and (3) whooping-cough. In the second those without dyspnœa or cyanosis are found: (4) paroxysmal tachypnœa; (5) the air-hunger of diabetes mellitus and the allied condition in uræmia ; and (6) periodic respiration in its two forms-viz., grouped respiration and Cheyne-Stokes breathing.

1. Asthma.-When speaking of asthma I mean, of course, spasmodic asthma or true idiopathic asthma, and I do not include any other forms of paroxysmal dyspnœa, often incorrectly called asthma, for these have entirely different pathological causes and run different clinical courses. Asthma is a widespread spasm of many groups of the respiratory muscles. The chest is almost fixed in the position of deep inspiration, the diaphragm depressed and almost immobile, and the bronchial muscle contracted. These are all coördinate phenomena, and no one of them can be regarded as the primary or initial cause, to which the others are secondary. This in especially true of the spasm of the bronchial muscle, for though the bronchial muscle exists and is probably in a condition of spasm, there is no proof that this alone is capable of producing all the phenomena of asthma.

In an attack of asthma the respiratory rhythm is entirely altered. The breathing is slow, with a greatly prolonged expiratory phase. The post-expiratory pause is absent and a post-inspiratory pause present instead. The inspiratory muscles are in full action, but there is little or no expiratory recoil, and the dy-pnoea which results is obviously the result of the restricted ebb and flow of air due to the defect of expiratory contraction. The passing off of the attack is indicated by the slow and gradual return of the expiratory movements. It may sometimes pass off as suddenly as it came on, but as a rule recovery is slow, as it must be if the spaim has been of any duration, for elastic and muscular tissue kept long upon the stretch loses its tone and only slowly regains it. Although as the result of repeated attucks the nutrition of the lungs may suffer and chronic bronchitis and emphysema result, still asthma stands in no other necessary relation with these two diseases.

The extraordinary facr about asthma is the variety and multiplicity of causes which evoke an attack. Yet the individual must be asthınatic - that is, predisposed - for the same irritation which excites an $a^{t}$ tack in such an individual will have no such effect in a normal person. It is this underlying predisposing condition which is the essential factor in asthma. This cannot be seated in the respiratory centre in the medulla, but mant be looked for in centres above this, possibly in the b"ain itself, though we do not know where. We might call this the asthmatic centre.

Assuming such a predi-position or centre, we may construct a diauram showing the various exciting causes of the attack. (Fir. 3.) An exactly similar diagram could be constructed for epilepsy, showing a similar variety of exciting causes and involving a similar centr.l predisposing condition, though, of course, it could not be called a centre. Asthma bears a close 
resemblance to epilepsy in other respects. Thus it is often preceded by some definite premonitory symptom, answering to the aura of epilepsy, and the removal or treatment of it may ward off an attack of asthma just as the treatment of the aura may prevent an epileptic fit.

Again with asthma, as with epilepsy, after an attack the patient may be exposed with impunity to the cause which at other times would withont fail excite an attack. Like epilepsy, asthma is often hereditary or rums in families, and may give evidence of itself in the early years of childhoorl. It stands also in close relation with some other neurotic conditions, many of them hereditary and running in families,

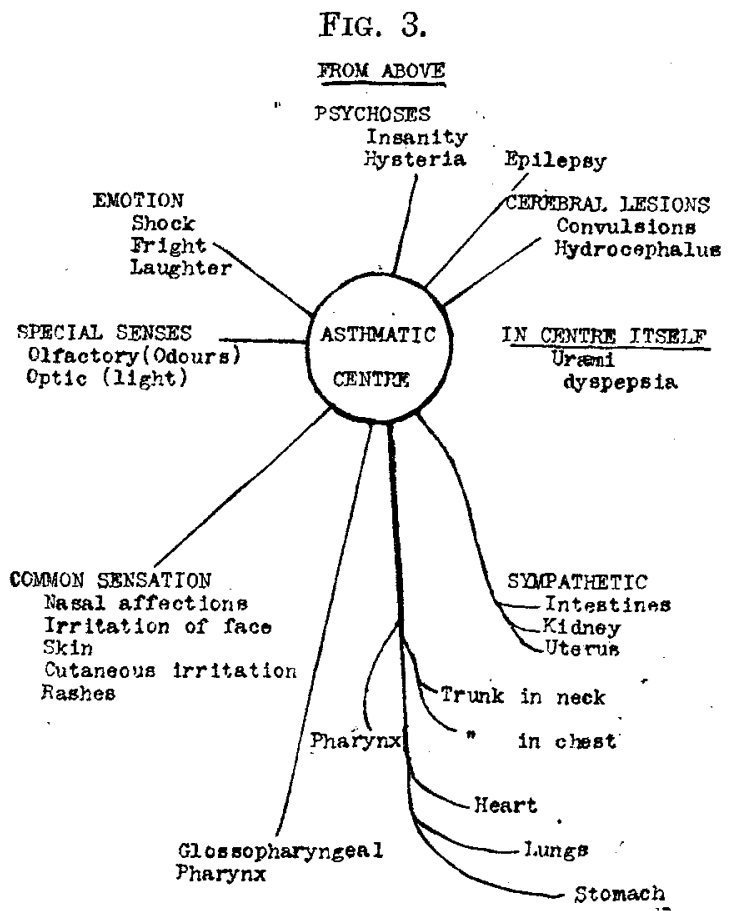

Diagram of exciting causes of asthma.

such as paroxysmal sneezing and coryza. As epilepsy, except when associated with organic disease of the brain, is bilateral, so asthma affects both sides, and unilateral asthma is unknown.

A remarkable fact about asthma is that the development of organic disease of the lungs on the one side or of the central nervous system on the other may lead to the disappearance of the asthma to which the patient till then had been subject. Thus I have known a patient, asthmatic for years, to develop phthisis about the age of 45 , and never have an attack of asthma afterwards. So, too, asthma may alternate with epilepsy and insanity. A very remarkable series of cases of this kind was published some years ago by Savage and Conolly Norman, ${ }^{2}$ of which I mention a few in abstract as examples.

A woman, aged 34, without any insane inheritance, had been a patient in an incurable hospital for some years with chronic asthma. She became for the second time insane, and lost her asthma. She continued insane until an attack of asthma came on and then began to recover During convalescence she had butfew attacks of asthma, but when well the asthma returned with greater violence than ever

A female, aged 28, with a history of insanity on the mother's side and of phthisis on the father's, became asthmatic at the time of menstruation and continued so for six years, when she became insane. During her insanity she was free from asthma, but with mental health the asthma returned. She had two subsequent attacks of insanity with the some sequence of events.

A man, aged 28, with a history of insanity on both sides, suffered from asthma for seven years, for which he took large amounts of morphia. He then became insane but free from asthma for seven months. The asthma then returned and the patient recovered his senses, and remained mentally well, but subject to asthma.

Salter described a remarkable case in which asthma alternated with epilepsy, and was on each occasion preceded by the usual aura, the only difference being that asthma sometimes followed instead of the fit. Similar instances have been recorded of the alternation of asthma and hemicrania and of asthma and hysteria. These and similar considerations lead, necessarily it would seem, to the conclusion that the asthmatic condition must be of central localisation, and that asthma must therefore be regarded not as a respiratory disease but as a central respiratory neurosis.

2. Laryngismus stridulus is generally recognised as standing in very close relation with fits, and it has even been described as a laryngeal convulsion. This also, then, by the same proces $\mathrm{s}$ of reasoning, may be presumed to be a respiratory neurosis of central origin. I have seen laryngeal spasm occur in the course of hysteria, as a transient phenomenon, alternating with other functional affections of the larpns--e.g., with adductor paralysis. Strange to say, in this case there were attacks of transient paralysis of one half of the diaphragm.

3. Thooping-cough.-It may seem lash without discussion to place whooping-cough among the respiratory neuroses. Consideration of all the facts of the disease appears to warrant the conclusion that whooping-congh is an infectious zymotic disease, the stress of which falls chiefly on the upper respiratory centres. This is associated witl local manifestation in the air-passages in the form of a peculiar or specific catarrh, many of the pulmonary changes being the mere mechanical resilts of the violent conghing:

I now jass to the second gromp of respiratory neurosesviz., that in which there is no interference with the aeration of the blood, and consequentiy no cyanosis or suffocation.

4. Paroxysmal tachypnox. -This has been called hysterical asthma. Asthma it certainly is not, and hysterical in this connexion means nothing more than emotional or functional. The condition is very interesting and remarkable, and, I believe, rare. The attacks often come and go with great abruptness. During the attack the respirations may be very rapid, even reaching 100 or nore in the minute, and may be considerably in excess of the pulse beats. I have seen the respirations 100 while the pulse was only 80 . The breathing. is noisy, panting, or puffing, the face is flushed, the cheeks and lips rosy red, with no trace of blueness. The air passes freely in and out of the lungs, and the movements are all exaggerated. The attacks seem to cause no distress. Yet if a normal person tried to breathe at the rate of 100 even for one minute the effort would be found to be consiclerable, and after another minute or so would become exhausting. Yet attacks of tachypnoa may last from 2 to 3 hours and may recur at short intervals, so that the whole period of liability may extend to several weeks. The condition is strictly comparable with tachycardia. In each the attack may begin and end in the same curiously abrupt way without apparent cause, and the patient appears to be hardly conscious of the condition, and to suffer little os no distress from it. 'The patients are usually young, nervous, emotional women. I do not remember ever to have seen tachypnoea in a man. The attacks rlo not seem to be in any way under the patient's control or to be capable of being evoked spontaneously.

Tachypnœa must be regarded as a condition of diseasc, and as strictly pathological and so far important, though it has not the serious significance that tachycardia often has-I have never seen it lead to any serious result or associated with any definite nerrous or physical defect. Paroxysmal tachypnoea should, therefore, be placed among the respiratory neuroses in a category by itself, just as paroxysmal tachycardia is among cardiac disturbances.

5. The ain'-hunger of diabetes mellitus and uromid. In the air-hunger of diabetes mellitus the respirations are greatly accelerated, free, and deep. The noisy puffing and panting have suggested the name of steam-engine breathing. The lesion is one of the respiratory mechanism affecting the higher respiratory centres, and not of the respiratory organs, and this is confirmed by its association, sooner or later, with coma. The development of the full stage is often preceded by various respiratory disturbances, such as sighing and irregular breathing, which may come and go, and give an indication of what is threatening some time before it comes. The onset is in most cases abrupt, sometimes extremely so, the patient passing in the course of a few minutes into the condition described. The coma comes on more gradually, so that for some time the patient, though showing the typical air-hunger, is quite conscious, and capable of mental effort, and apparently is but little distressed. Similar symptoms, though rarely so marked, may arise in the course of uræmia, but they are, as a rule, less sudden, and more often preceded by irregularities of respiration. In both cases I suppose the exciting cause must be some chemical body, but its nature is unknown, and the difficulty in either case is to explain its sudden abrupt development.

6. Periodicrespirations. - The respiration may become irregular from various causes, but for the most part these irregularities are themselves of irregular recurrence. But sometimes these irregularities recur at regular interrals, each 
group of irregularities presenting the same general characters. This peculiar breathing is called periodic or grouped respiration. Of periodic respiration there are two special typesth: one well known as Cheyne-Stokes breathing; the other not so generally recognised, and termed grouped respiration. The two types stand in the strongest possible contrast with one another, as the two tracings clearly show.

\section{FrG. 4.}

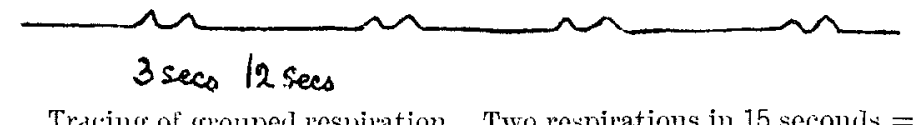
8 in minlute.

FIG. 5.

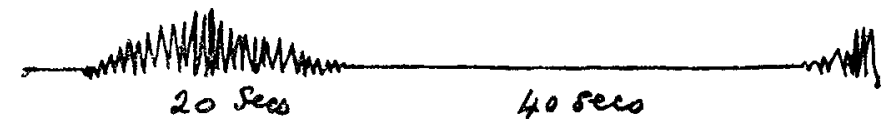

Tracing of Cheyne-Stokes breathing. Forty respirations in 20 seconds; respiration-rate $=120$ in ninute.

Grouped respiration. - In grouped respiration the respirations are slow, and number not more than:from 8 to 12 in the minute, occur in groups of two or three, are of equal depth and regular in frequency, while the intervals between the groups are comparatively short. This form is rarely seen except in the coma stage of meningitis in childhoorl, especially so far as my experience goes in the posterior basic form. It is an interesting phenomenon, but is in itself of no special significance.

Cheyne-stoles breathing. - In Cheyne-Stokes breathing, on the other hand, the respirations during the breathing stage are extremely rapid. 'This phase may last 20 seconds, and during that time the respirations may number 40 i.e., be at the rate of 120 a minute. The striking peculiarities of Cheyne-Stokes breathing are the crescendo and diminuendo of the respirations in respect both of depth and noise, and the long pauses which follow the breathing phase, which may last $40-45$ seconds.

The prognostic significance is equally strongly contrasted in the two cases. Thus grouped respiration is simply an interesting phenomenon in the course of a serious nerrous affection, of itself likely to prove fatal, but clisappearing if the disease shonhl run a favourable course. It has, therefore, no special or grave significance. Cheyne-Stokes breathing, on the contrary, is of the gravest possible significance, and may of itself give warning of what is to be the result, when there might otherwise seen to be no special reason for alarm.

Cheyne-Stokes breathing is described as occurring in a very great variety of pathological conditions, but they all fall into two main categories: (1) where it occurs in the course of some disease or morbid condition of the central nervous system above the medulla: and (2) where there is heart failure of some kind, usually of the left ventricle. Cheyne-Stokes breathing has been described, though a rare occurrence, in healthy persons, during sleep, after great fatigue, or in advanced life. It has also been present as a personal or family peculiarity in healthy persons who have lived to a good old age. Besides this it has been met with after the use of certain drugs--e.g., bromide of potassium, chloral and morphia, and others, disappearing after the effect of the drugs had passed off. In animals, again, periodic respiration more or less closely resembling Cheyne-Stokes breathing has been observed during sleep and hibernation, after muscular fatigue, after the administration of many drugs, and in experiments upon the medulla and brain, or upon the heart and circulation.

Interesting as all these observations are, and important as they may be in the attempt to find a general explanation of the phenomenon, they should not be introduced into the consideration of Cheyne-Stokes breathing as a pathological and clinical condition.

When Cheyne-Stokes breathing is observed in men it may be concluded that the patient is probably suffering either from heart failure or from some disease or morbid condition of the central nervous system above the medulla and pons. Yet it is not a necessary accompaniment of any affection in either group, and is, in fact, far more often absent than present in all of them. It must therefore depend upon some accidental condition which is more likely to arise in one of these two gruups of affection than in any other. But what the condition is there is nothing yet to show.

Various phenomena have been associated with the different phases of Cheyne-Stokes breathing, such as change in the rate, tension or general characters of the pulse, alterations in the pupils, variation in the dyspnoa and cyanosis, but none of these are constant in all cases alike, or, indeed, in the same case at different times, while they may each and every one be entirely absent, so that no one of them can be the essential or determining cause. 'They must all be merely accidental, and the result of the morbid condition to which the Cheyne-Stokes breathing itself is due. It follows that all explanations which pre-suppose any of these plienomena must fall to the ground.

Cheyne-Stokes breathing, after being well marked, may intermit and disappear for a time entirely, the respiration returning to the normal. More often the characteristic features are incompletely developed. Thus the pauses may be very short or absent, while the crescendo and diminuendo of breathing may be well marked, or the breathing may be regular and but little accelerated, yet there may be at regular intervals intermission of two or three respirations, or their place be taken by a long-drawn sigh. At other times the breathing may be irregular, but not periodic. Lastly, the pauses may be present at certain times only-for instance, cluring sleep, but, on the other hand, they may also occur only when the patient is awake.

From all these considerations we arrive at the conclusion that the automatic centre in the medulla is doing its rork well, thongh in a somewhat unusual way, but that its action is hampered or interfered with, so that the cause must be looked for not in the medulla but in some part of the nervous system above that level, and therefore probably in the brain itself, and this view is confirmed by the fact that with definite organic disease of the medulla and pons Cheyne-Stokes breathing is unknown. Under these circumstances the general cereural and mental condition of the patient becomes of interest, and this is best observed in the cardiac group, when the patient is generally not unconscious. It is remarkable that the patients themselves seem to be but little disturbed by their peculiar breathing, and, indeed, to be unconscious of it. Thus, they may stop speaking in the middle of a sentence when the pause come on, and complete the sentence after the pause is orer. without seeming to be aware of the break, though the intelligence may be clear. If told to breathe or marle to speak during the pause, they do so with an effort, and only after bringing into play the extraordinary respiratory muscles. So that it is evident that it is the voluntary respiratory centres that are chiefly affected or hampered in their action.

The general consideration of each of the respiratory neuroses alike seems to lead to the same conclusion-viz. that it is not the respiratory centre in the medulla that is at fault, but some higher coördinating centres possibly in close relation with the other centres of volitional action, and therefore presumably in the cortex of the brain. In this connexion the physiological considerations with which the paper opened are of importance. It is obvious that a view of this kind is likely to modify considerably the lines of treatment to be adopted, but to discuss this now would take me too far afield.

Wimpole-street, $W$.

Donations and Bequests.-By the will of Mrs. Alice Millar, of Holloway Sanatorium, Virginia Water, the testatrix bequeathed $\$ 5000$ each to the Royal London Ophthalmic Hospital, the Cancer Hospital, and the Royal Society for the Prevention of Cruelty to Animals. - A gift of $£ 1000^{\circ}$ has been received by the town council of Campbeltown for building an addition to the infectious diseases hospital with the object of accommodating consumptive patients. - Prince Christian has sent a cheque for $£ 1557$, the balance of the Windsor Memorial Fund to the late King Edward VII., to the chairman of the King Edward VII. Hospital, Windsor.-Mr. Austen Chamberlain has received $£ 250$ from the Union-Castle Steamship Company towards the $£ 100,000$ he is raising for the London School of Tropical Medicine.-A cheque for $£ 1000$ has been received by the treasurer of the St. Mary's Hospitals, Manchester, from Mr. Edward Graham Wood, of Salford and Southport. It was decided to name one of the beds after Mr. Wood's granddaughter, "The Sada Joyce Holden Berl."-.The Chelsea Hospital for Women has received donations of $£ 5210$ s. towards its rebuilding fund from Sir Samuel Provis, K.C.B., and Mr. George Millington. 


\section{REMARKS ON THE}

\section{TREATMENT OF SARCOMA OF THE LONG BONES. ${ }^{1}$}

\author{
BY SIR FREDERIC EVE, F.R.C.S. ENC., \\ SENIOR SURGEON TO THE LONDON HOSPITAL, ETC.
}

MY remarks on the treatment of sarcoma of the long bones must necessarily, owing to the short time at my disposal, be mainly concerned with general principles. The sarcomata fall, for purposes of treatment, into three groups : (I.) periosteal sarcomata; (II.) central sarcomata composed of round and spindle cells; (III.) myeloma (myeloid sarcoma). The last-named must be differentiated from the diffuse or generalised hyperplasias of medullary tissue met with in albumosuria and other affections, and to which the term "myeloma" is also applied.

\section{I.-Periosteal Sarcomata.}

The periosteal sarcomata spread locally along the periosteum, endosteally through the medulla, and also along the muscles attached to the affected bone. Extension into the veins is so early that in many cases, especially of sarcoma of the femur and humerus, metastases are already present when the patient first comes under observation. Sarcomata of these bones frequently involve the axillary and femoral glands respectively.

Amputations in periosteal sarcoma must remove the affected bone in its entirety, and if possible the whole or a considerable part of the length of any muscles attached in the neighbour hood of the tumour.

Owing to the rapid growth of sarcomata of the humerus the fact that they usually originate in the upper third, and their tendency, wherever arising, to involve the whole length of the bone, the interscapulo-thoracic (Berger's) operation will be required, except in the rare instances in which there is a growth confined to the lower third, when amputation at the shoulder-joint may suffice. Butlin" states that "there is no tendency to affection of the axillary glands," but the truth of this I doubt.

Notwithstanding arguments in favour of non-intervention based on the failure of treatment, I think that a patient with periosteal sarcoma of the femur should be given the remote chance afforded by amputation at the hip-joint. The immediate clanger of the operation is slight. I have since 1896 performed 11 consecutive amputations at the hip-joint without a death. We can only hope that in the future the practitioner who first sees the patient, assisted as he is by the $X$ rays in diagnosis, will send patients for surgical treatment immediately, and that our statistics may thereby be improved. The femoral lymphatic glands are often palpably enlarged, and I have for many years been in the habit of removing them in the preliminary stage of the operation. The anterior racket incision has been used, the artery and vein being tied, and the glands dissected out through the first incision. In tumours situated high up in the femur I have dissected the attachments of the muscles cleanly from the os innominatum. The practice of a preliminary ligature of the main vessels, the injection of cocaine into the nervetrunks before division, and other methods of combating shock, have greatly diminished the immediate mortality in high amputations at the shoulder and hip. I have frequently injected saline and brandy directly into the femoral vein before closing the wound.

The common periosteal sarcomata of the upper third of the tibia and those of the upper third of the fibula, together with rare tumours of the same nature in the forearm (usually in the upper third), should be treated by amputation at the lower third of the thigh and humerus respectively. In tumours of the lower third of the leg amputation throngh the kneejoint may be done. Considerable enlargement of the femoral glands in growths of the middle and upper third of the tibia has been noted by me. These have been removed, and although the pathologists reported that the enlargement was

1 A paper read betore the Surgical Section of the Royal Society of Medicine on Nov. 12th, 1912 view. not due to malignant disease, I must own that $I$ received this information with scepticism.

Sarcomata of the ribs are rare. They may now be dealt with safely owing to the recent methods of opening the pleura.

In regard to microscopic structure, after admitting that the round-celled sarcomata are the most malignant, I agree with Butlin that the metaplasia of part or the bulk of the tumour into cartilage or bone does not affect its malignancy, and therefore does not modify the treatment.

\section{II.-Central Sarcomatc Composed of Round, Spindle, or Mixed Cells.}

We owe our knowledge of the lower degree of malignancy of central tumours, together with much more in the natural history of malignant diseases of the bones, to the painstaking work of Butlin. Their relative benignity must be ascribed to their being surrouncled by a capsule of bone, but we must not overlook the fact that in many instances there is a wide infiltration of the medulla, and in some the bony capsule has been broken throngh. When this has occurred they should, I think, be treated on the same lines as periosteal sarcomata. Otherwise it would appear safe to amputate through the affected bone some distance above the disease if it occupies the distal end, or throngh the joint immediately above if it occupies the proximal end of the bone. Central tumours of the lower end of the radius and ulna are less malignant than those of other bones. Butlin quotes $^{3}$ a case of spindle-celled sarcoma of the lower half of the ulna which was treated by erasion, and the patient was well two vears later; and again, ${ }^{\frac{1}{4}}$ a case of spindle-celled sarcoma of the external condyle of the femur treated by resection. The patient was in good health three years later. On the other hand, in an example of central sarcoma of the upper epiphysis of the femur, the patient died from the operation, and was found to be already suftering from metastases. ${ }^{3}$ The tumours under consideration are rare, and therefore the experience of individual surgeons is very limited. If we are to learn more of the later histories of patients, it must be by a combined system of regis. tration at the various hospitals by which the patients are followed up.

I offer the above remarks on the treatment of this group in a tentative manner, and hope to learn the opinion of other surgeons. These growths, if well localised, and especially if spindle-celled, offer a tempting field for resection and the employment of the various methods of osteoplasty to be alluded to later.

\section{III.-Myeloma (Myeloid Sarcona)}

Although it has long been taught that the true myeloma has a low degree of malignancy, yet it is only in recent years that it has been recognised as possessing, at least in some situations, a purely local malignancy. Butlin, even in 1900 , classes the central round-and spindle-celled sarcoma with the myelomata under the common heading of central tumours, in discussing their treatment. The broad general statement made in most text-books that the myelomata are only locally malignant requires, however, considerable modification. The myelomata of the femur, and especially those of the upper end of the humerus, are sometimes followed by metastasis. According to Butlin's statistics, the tumours were giant-celled sarcomata in three out of five patients who died with metastasis after amputation of the femur for central sarcoma. ${ }^{6}$ And in two out of three un successful cases of sarcoma of the upper end of the humerus two were described as myeloid sarcoma. Both died from metastasis after the performance of Berger's operation. Kausch ${ }^{\top}$ describes a case of myeloid sarcoma of the upper end of the humerus, treated in 1902 by resection and implantation of two sterilised portions of humerus. Recurrence necessitated amputation at the shoulder joint. Death occurred from metastasis 11 months after the first operation.

Our London Hospital statistics throw little light on this question, as all the cases involving the femur and humerus were treated by amputation. They, however, emphasise the benignity of myeloma of the tibia and fibula. $\mathrm{Mr}$.

3 The Operative Surgery of Malignant Disease, p. 52. 4 Op. cit., p. 52.
6 Op. cit., p. 53. 